\title{
AVALIAÇÃO DA DISPERSÃO ESPACIAL DA PLUMA DO ESTUÁRIO DO RIO ITAJAÍ-AÇU EM DIFERENTES PERÍODOS DE DESCARGA
}

\author{
TROCHIMCZUK Fo., A. \& C.A.F. SCHETTINI \\ Lab. Oceanografia Física - CTTMar/ UNIVALI - Cx. P. 360, Itajaí, SC - 88.302-202 \\ anatole@cttmar.univali.br - guto@cttmar.univali.br
}

\begin{abstract}
RESUMO
Este trabalho apresenta uma avaliação da dispersão da pluma do estuário do rio Itajaí-açu sob diferentes condições de descargas fluviais. Três cruzeiros oceanográficos foram realizados, em janeiro, fevereiro e março de 2000, na plataforma interna adjacente à desembocadura do estuário para levantamento de dados de salinidade, temperatura e material particulado em suspensão (MPS). As descargas fluviais apresentaram-se com 556, 227 e $214 \mathrm{~m}^{3} / \mathrm{s}$, respectivamente, para as campanhas de janeiro, fevereiro e março. Os resultados mostraram que a descarga fluvial é o fator determinante das características da pluma. A concentração de material particulado em suspensão e a proporção de água doce na pluma costeira é proporcional à amplitude da descarga fluvial. Em todas as campanhas as plumas apresentaram deflecção em sentido nordeste.
\end{abstract}

Palavras chave: plumas costeiras; descarga fluvial; rio Itajaí-açu

\section{VALUATION OF SPATIAL DISPERSION OF ITAJAÍ-AÇU ESTUARINE PLUME IN PERIOD OF DIFFERENT DISCHARGE}

\begin{abstract}
This paper presents an assessment on the dispersion of the Itajaí-Açu estuary plume under different river discharge conditions. Three oceanographic cruises were carried out at January, February and March 2000 on the adjacent shelf off Itajaí, when salinity, temperature and particulate suspended matter data were acquired in vertical profiles using a ctd probe. The river discharges during the cruises were 556, 227 and $214 \mathrm{~m}^{3} \cdot \mathrm{s}^{-1}$, respectively. The results pointed out that the river discharge is the main factor driving the plume dispersion. The concentration of the particulate suspended matter and the proportion of fresh water is directly related to the discharge. It was observed also that the plume dispersions is predominantly towards Northeast.
\end{abstract}

Keywords: coastal plumes; fluvial discharge; Itajaí-açu river

\section{INTRODUÇÃO}

As plumas costeiras podem ser classificadas como plumas fluviais e estuarinas. No primeiro caso, há um domínio da descarga do rio sobre os efeitos de marés resultando em uma liberação direta de água doce continental em direção ao mar. No segundo caso, os efeitos das marés dentro do estuário promovem a mistura da maior parte da água provinda da drenagem continental (Mann \& Lazier, 1991). Os dois tipos de plumas poderão ocorrer 
associados a um estuário devido às variações de descarga e amplitude de maré.

A expansão da pluma sobre a água costeira depende basicamente de dois parâmetros, a diferença de densidade relativa entre a pluma e camada de água subjacente e o número densimétrico de Froude (Wrigth \& Coleman, 1971 apud Bowden, 1983). Se não há mistura significativa das águas através da interface, a pluma vem a ficar necessariamente mais fina em sua dimensão vertical ao mesmo tempo em que se espalha lentamente (Bowden,1983).

Muitos cientistas têm realizado estudos com plumas costeiras através de diferentes técnicas metodológicas. Tais técnicas compreendem-se principalmente em observações "in situ" (Broche et al., 1998; Hoekstra, 1989; Hoyal et al., 1999), estudos através de sensoriamento remoto (Geyer et al., 2000, Froidefond et al. 1998) e modelos numéricos (Morehead \& Syvitski, 1999; Poulos \& Collins, 1994, Garvine, 1987), sendo considerável também a utilização composta com mais de uma técnica.

No Brasil poucos estudos foram realizados sobre plumas costeiras. Os primeiros estudos foram na foz do rio Amazonas, avaliando a dispersão espacial da pluma através de vários perfis que se estendiam por mais de 300 km em direção ao mar (Geyer et al., 1991). Através de um estudo da produção fitoplanctônica e bacteriana da pluma costeira da Lagoa dos Patos - RS, Abreu et al. (1995) observou um forte gradiente crescente de salinidade na superfície em direção ao oceano. Schettini et al. (1998), estudaram a pluma estuário do rio Itajaí-açu em um período de alta descarga enfatizando-se aspectos ecológicos e oceanográficos.

O objetivo do presente trabalho é descrever e comparar minuciosamente as condições oceanográficas ao largo da desembocadura do rio Itajaí-açu na região de influência da pluma, em diferentes condições de descarga no verão.

\section{MATERIAIS E MÉTODOS}

Através de um convênio entre a Universidade do Vale do Itajaí e a Universidade de Kiel - Alemanha, foram realizados três cruzeiros oceanográficos com propósito investigativo na região costeira ao largo da desembocadura do estuário do rio Itajaí-açu, nos dias 17 de janeiro, 25 de fevereiro e 14 de março de 2000 (Figura 1).

Em todos os dias de campanha a pluma costeira diferenciava-se visualmente da água costeira por apresentar uma água mais turva. O posicionamento das estações de coleta apresentaram-se de forma distinta entre os cruzeiros, com uma certa similaridade entre as estações de coleta dos cruzeiros de janeiro e de março por formarem linhas perpendiculares à costa. No cruzeiro de fevereiro foram realizados dois transectos em forma de " $X$ " sobre a pluma (P2 e P3) e um transecto perpendicular à costa mais ao sul (P1). As coordenadas das estações foram posicionadas com um receptor de GPS marca GARMIM modelo $12 \mathrm{XL}$, e em cada estação foram realizados perfis verticais para aquisição de dados com uma sonda do tipo CTD MEGrisard $^{\mathrm{TM}}$ operando a $5 \mathrm{~Hz}$. Dados de pressão, salinidade, temperatura e transmissividade luminosa foram mensurados da superfície ao fundo. A salinidade foi aquisitada através da medição da condutividade elétrica da água e a turbidez foi medida com um transmissômetro com $1 \mathrm{~cm}$ de trajeto ótico. Posteriormente os dados foram reduzidos através de uma rotina em ambiente Matlab ${ }^{\mathrm{TM}}$ para tornarem-se equiespaçados verticalmente em intervalos de $0,25 \mathrm{~m}$ de profundidade. Os dados de transmissividade luminosa (\%) foram convertidos em concentração de material particulado em suspensão - MPS ( $m g / l)$ utilizando-se uma curva de conversão obtida em laboratório (Brandt, 2000).

Dados de vazão diária do rio Itajaí-açu foram obtidos na estação limnimétrica de Indaial 

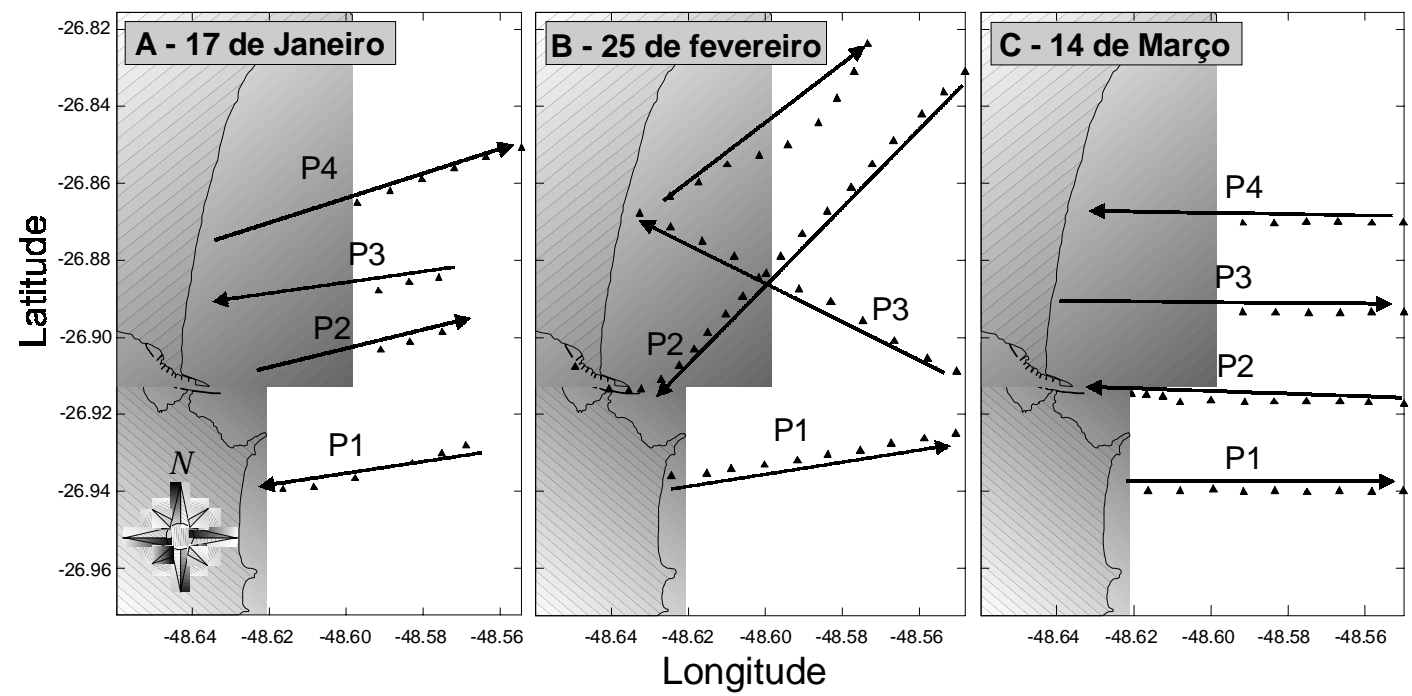

Figura 1 - Posicionamento das estações de coleta de dados na região costeira adjacente à desembocadura do estuário do rio Itajaí-açu durante os três cruzeiros realizados. As direções das setas indicam a direção em que as estações foram realizadas e a letra "P" com números de 1 a 4 representam os símbolos atribuídos para os transectos, sendo $A$, campanha de 17 de janeiro, $B$, campanha de 25 de fevereiro, e, $C$ campanha de 14 de março.

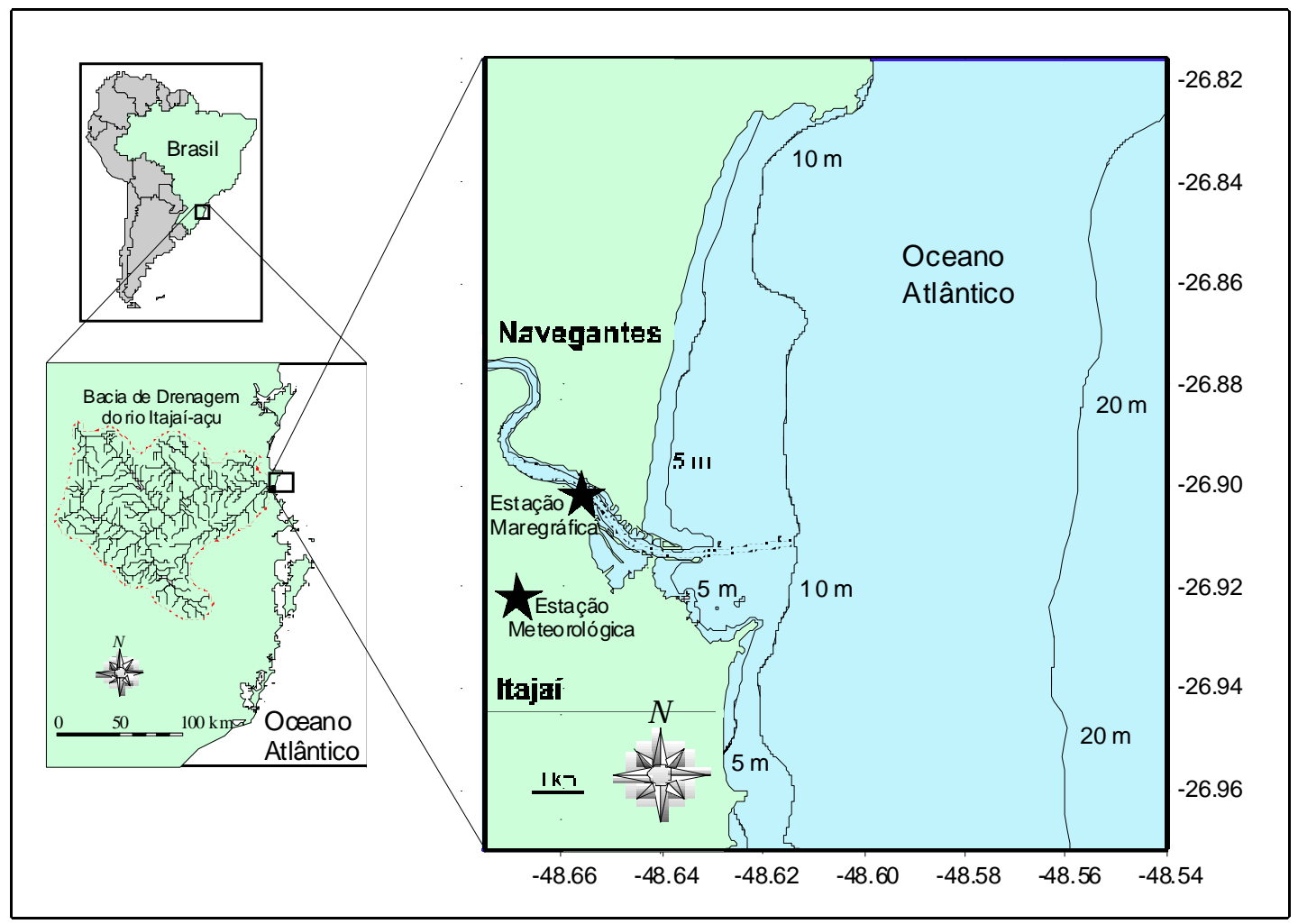

Figura 2 - Localização da área de estudo incluindo a bacia de drenagem, desembocadura do rio Itajaí-açu e região adjacente. 
- SC, Agência Nacional de Águas e Energia Elétrica.

Dados de marés foram cedidos pela empresa BALLAST HAM, a qual possui uma estação maregráfica situada dentro do estuário do rio Itajaí-açu, próximo à desembocadura (Figura 2). A aquisição dos dados pelo marégrafo foi feita em séries temporais de 20 minutos.

Dados de direção e intensidade de vento foram obtidos em séries temporais com intervalo de amostragem de 1 minuto através de uma estação meteorológica automática marca DAVIS modelo WEATHER MONITOR II, situada no Laboratório de Climatologia da UNIVALI de Itajaí - SC (Figura 2).

\section{RESULTADOS}

\section{Ventos}

Os ventos predominantes nos dias $16 \mathrm{e}$ 17 de janeiro vieram principalmente do quadrante sul-sudoeste (convenção meteorológica), num total de 20 horas de atuação. A velocidade média de vento foi de
$2,8 \mathrm{~m} / \mathrm{s}$. Ventos do quadrante sudoeste foram menos representativos, atuando por um período inferior a 10 horas (Figura 3).

Os ventos nos dias 24 e 25 de fevereiro não apresentaram um padrão direcional definido, apresentando variações do quadrante nor-nordeste, sul-sudoeste e sudoeste, com um período de atuação de 9 horas. A velocidade média diária foi de $5,9 \mathrm{~m} / \mathrm{s}$, apresentando um pico de $20 \mathrm{~m} / \mathrm{s}$ as 16:00 horas do dia 24 vindo de norte (Figura 4).

Nos dias 13 e 14 de março, os ventos variaram de nordeste, leste-nordeste, e sulsudoeste, com um período de atuação de 11 horas para cada quadrante. A velocidade média dos ventos nestes dias foi de $4.3 \mathrm{~m} / \mathrm{s}$. Ventos de nor-nordeste também atuaram de maneira menos representativa por um período de 6 horas (Figura 5).

\section{Marés}

Analisando-se um período antecedente a 5 dias das campanhas, observou-se que as campanhas do dia 17 de janeiro e 14 de março apresentavam-se no início do regime de sizígia,
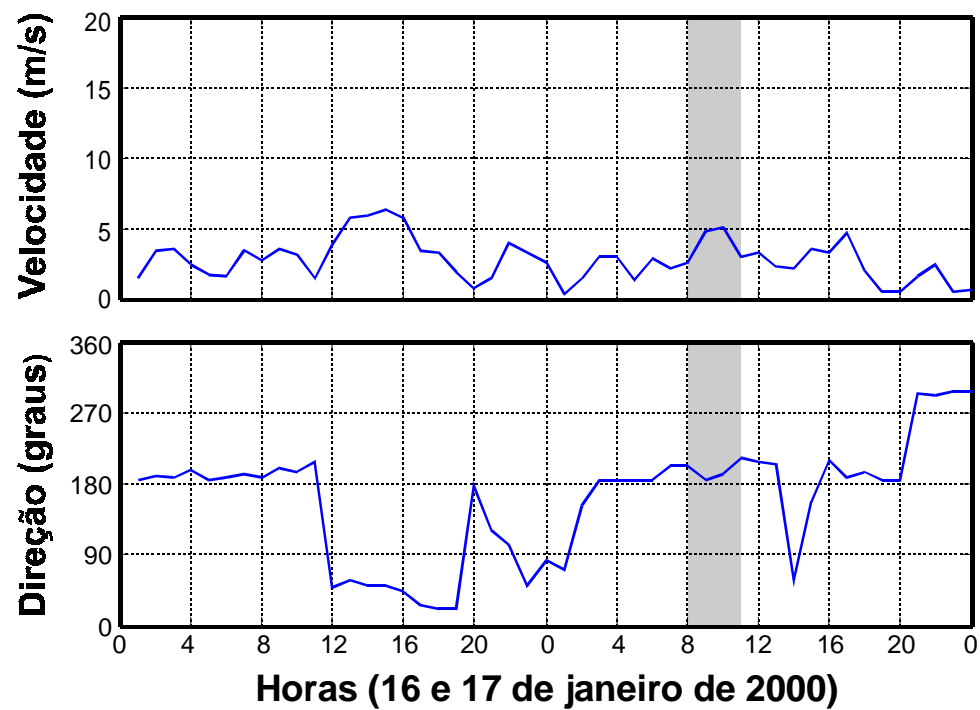

Figura 3 - Série temporal da velocidade e direção do vento para os dias 16 e 17 de janeiro de 2000. A região marcada indica o período em que foi realizado o levantamento. 

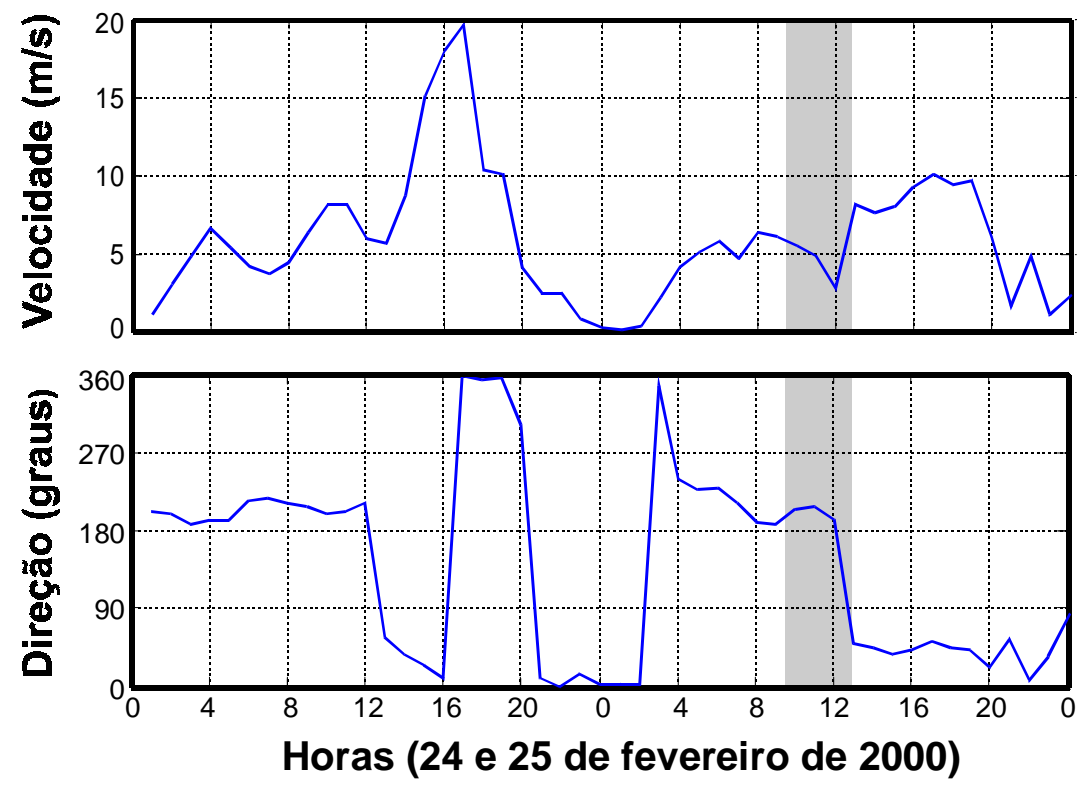

Figura 4 - Variação temporal da velocidade e direção do vento para os dias 24 e 25 de fevereiro de 2000. A região marcada indica o período que foi realizado o levantamento.
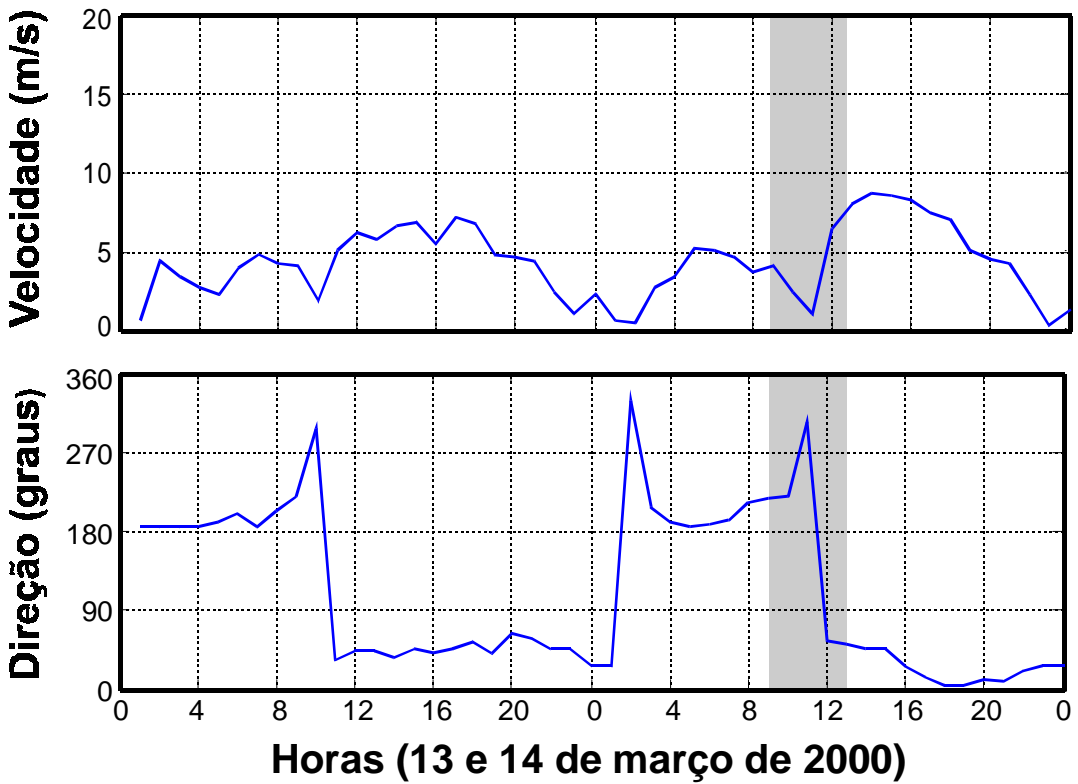

Figura 5 - Variação temporal da velocidade e direção do vento para os dias 13 e 14 de março de 2000. A região marcada indica o período que foi realizado o levantamento. 
ou fim de quadratura, com altura de $0,84 \mathrm{~m} \mathrm{e}$ $0,71 \mathrm{~m}$ respectivamente. A campanha do dia 25 de fevereiro apresentava-se no fim do regime de sizígia, ou início de quadratura, com altura de $0,61 \mathrm{~m}$.
Os níveis do mar médio durante as campanhasapresentaram-se aproximadamente com 0,7 m, 0,38 m e 0,41 m, respectivamente para as campanhas de janeiro, fevereiro e março.(Figuras 6, 7 e 8).

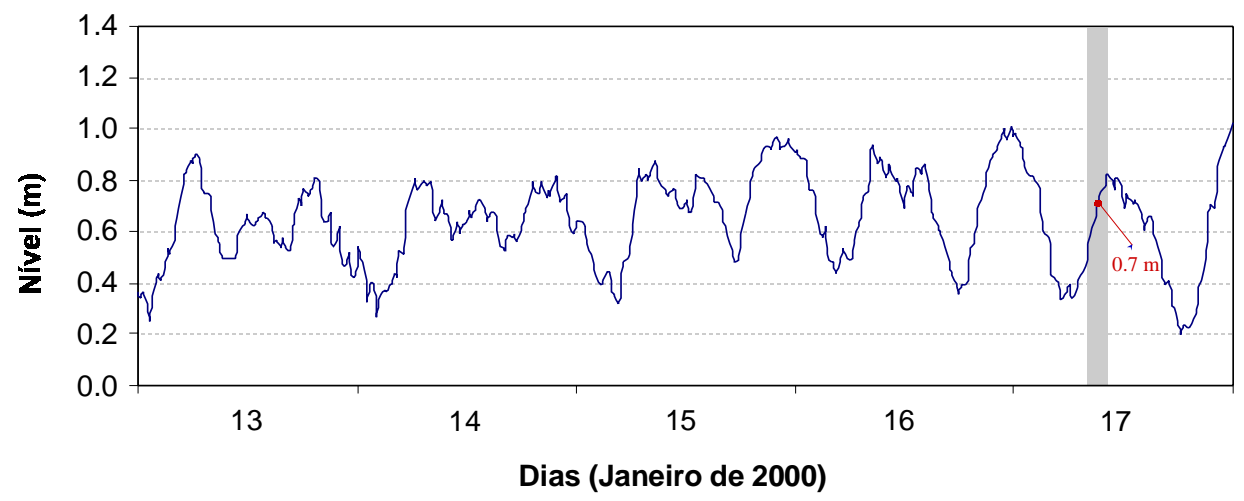

Figura 6 - Variação temporal da maré de 13 a 17 de janeiro de 2000. A região marcada indica o período que foi realizado o levantamento.

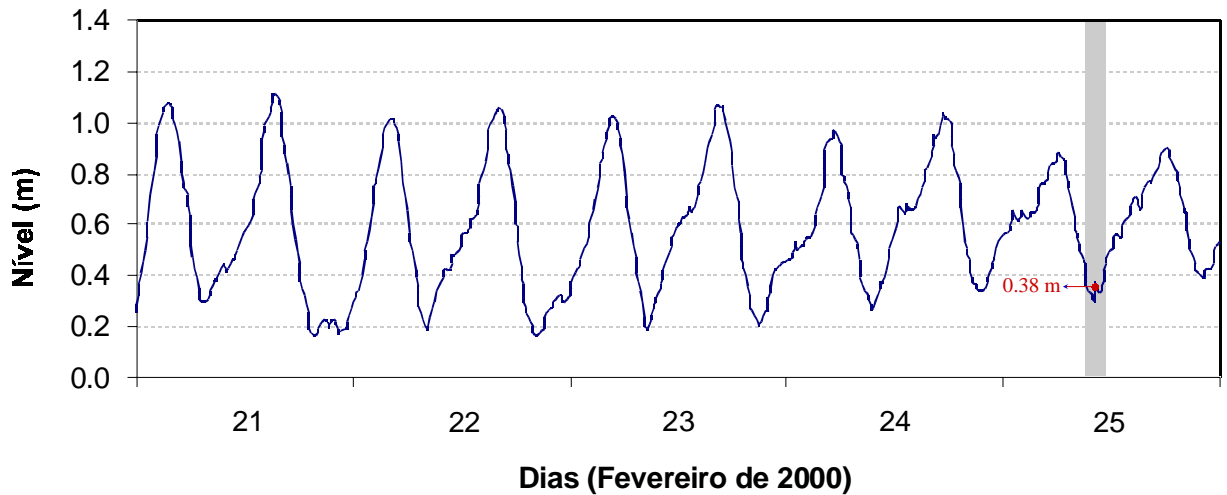

Figura 7 - Variação temporal da maré de 21 a 25 de fevereiro de 2000. A região marcada indica o período que foi realizado o levantamento.

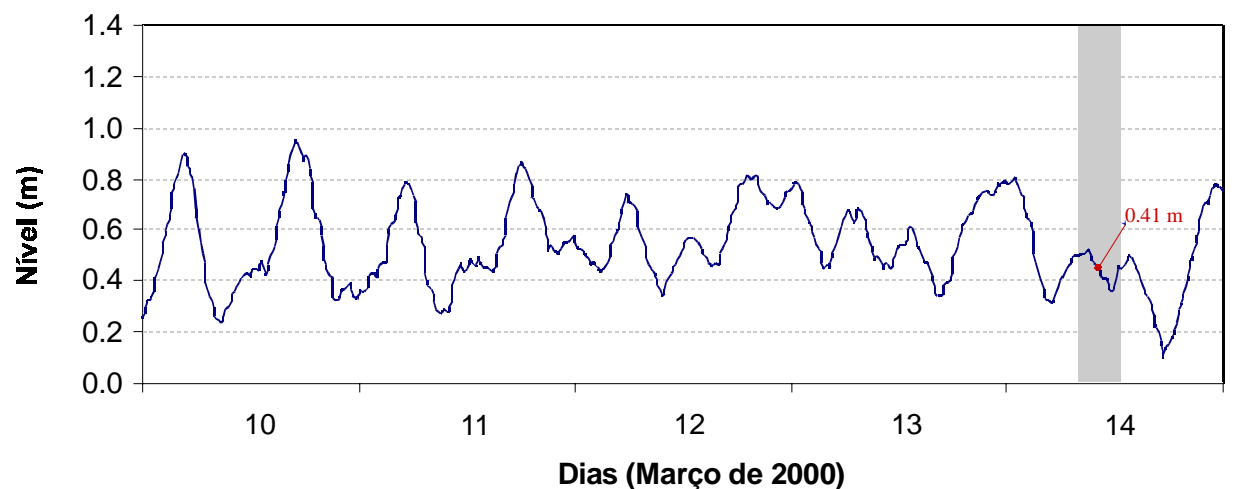

Figura 8 - Variação temporal da maré de 10 a 14 de março 2000 . A região marcada indica o período que foi realizado o levantamento. 


\section{Descarga fluvial}

A descarga fluvial apresentou-se com 556,227 e $214 \mathrm{~m}^{3} / \mathrm{s}$ respectivamente para as campanhas de janeiro, fevereiro e março. No período anterior à campanha do dia 17 de janeiro houve maiores descargas fluviais, apresentando valores de $939 \mathrm{~m}^{3} / \mathrm{s}$ no dia 15 de janeiro. No período anterior a 5 dias da campanha de 25 de fevereiro houve um pequeno aumento da descarga fluvial apresentando-se com $293 \mathrm{~m}^{3} / \mathrm{s}$ nos dias 20 e 24. Em março, 5 dias antes da realização da campanha do dia 14 , houve uma descarga de $404 \mathrm{~m}^{3} / \mathrm{s}$, que sucessivamente foi diminuindo com o passar dos dias (Figura 9).

\section{Condições oceanográficas}

\section{Diagramas T-S}

As campanhas de janeiro e fevereiro apresentaram três massas de água distintas, a água da pluma (APL), a água costeira $(A C)$ e a água de plataforma (AP) (Figura 10 e 11). Na campanha de março, além das três massas de água caracterizadas nas campanhas de janeiro e fevereiro, observaram-se também a água central do atlântico sul (ACAS), com temperatura inferior a $19^{\circ} \mathrm{C}$ e salinidade superior a 35 psu (Figura 12). Foi observado também nas três campanhas uma região com água costeira em formação (ACF), significativamente mais representativa na campanha de janeiro, e

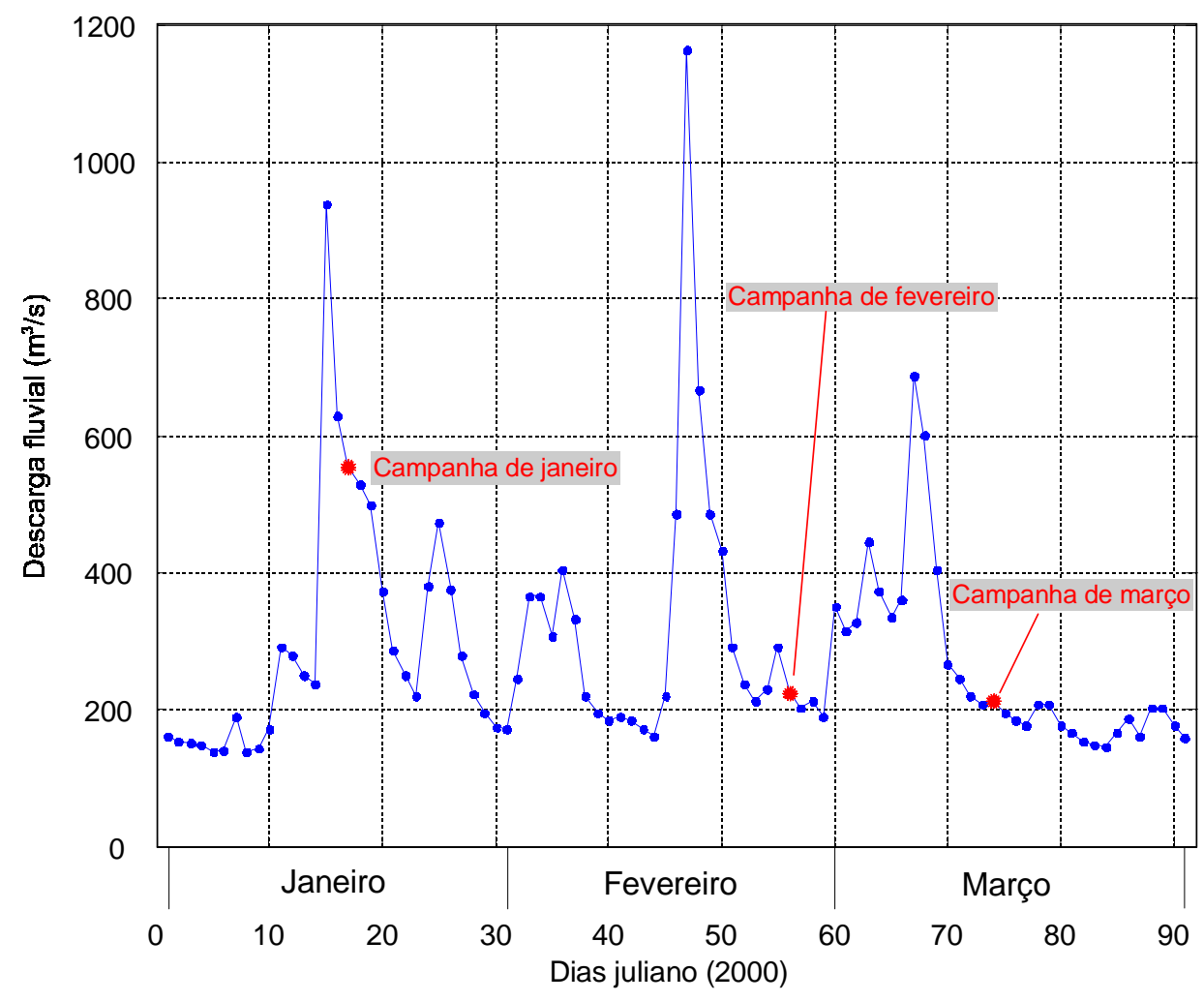

Figura 9 - Variação temporal da descarga fluvial do rio Itajaí-açu nos três primeiros meses do ano de 2000. 


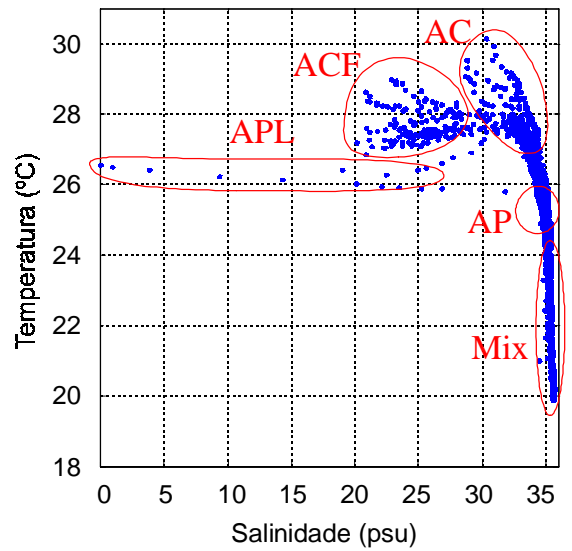

Figura 10 - Gráfico T-S da campanha do dia 17 de janeiro de 2000.

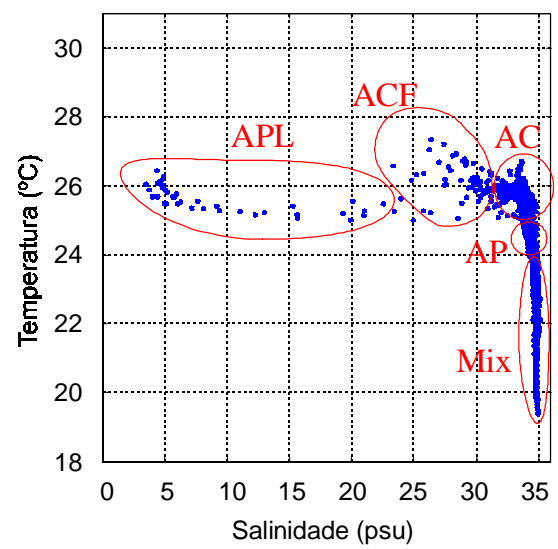

Figura 11 - Gráfico T-S da campanha do dia 25 de fevereiro de 2000.

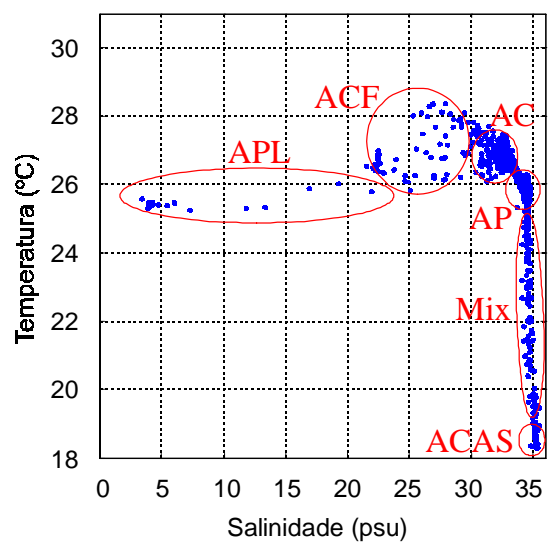

Figura 12 - Gráfico T-S da campanha do dia 14 de março de 2000. uma região de mistura de massas de água (Mix) influenciada pela AP e a ACAS.

2. Distribuição superficial das variáveis

\subsection{Campanha de janeiro}

A figura 13 apresenta a distribuição superficial de salinidade, temperatura e concentração de MPS na região costeira adjacente à desembocadura do estuário do rio Itajaí-açu. A salinidade apresentou-se baixa, menor do que 8 psu, próximo à desembocadura do estuário, com um forte gradiente crescente que se distribui de forma radial até a isohalina de 20 psu. No sentido sul o forte gradiente ainda apresentou-se até 30 psu. O aumento no espaçamento entre as isohalinas de 20 e 24 psu nos sentidos norte e nordeste indica o sentido de dispersão do campo de baixa salinidade (Figura 13a). A água da pluma após a desembocadura apresentou uma temperatura inferior a $27^{\circ} \mathrm{C}$ que progressivamente se mistura com a água costeira de maior temperatura, esta chegando a valores superiores a 29,5으. (Figura 13b). O material particulado em suspensão apresentou concentrações superiores a 150 $\mathrm{mg} / \mathrm{l}$ na região próxima à desembocadura, apresentando um forte gradiente decrescente que se distribui de forma radial. No sentido leste, o gradiente de MPS demonstrou-se inferior aos demais sentidos, o qual tornou-se evidente através do aumento do espaçamento entre isolinhas de concentração de 70 e 10 mg/l (Figura 13c).

\subsection{Campanha de fevereiro}

A Figura 14 apresenta a distribuição superficial de salinidade, temperatura e concentração de MPS obtido na campanha de fevereiro. As estações pertencentes ao transecto P2 acompanham o sentido de dispersão da pluma costeira, enquanto que o transecto P3 apresentou-se em sentido transversal a pluma. O campo de salinidade na superfície apresentou-se inferior a 8 psu na 
desembocadura e um sentido de propagação aproximado à nordeste representado pela isohalina de 28 psu. Na região próxima à desembocadura, entre as isohalinas de 8 e 16
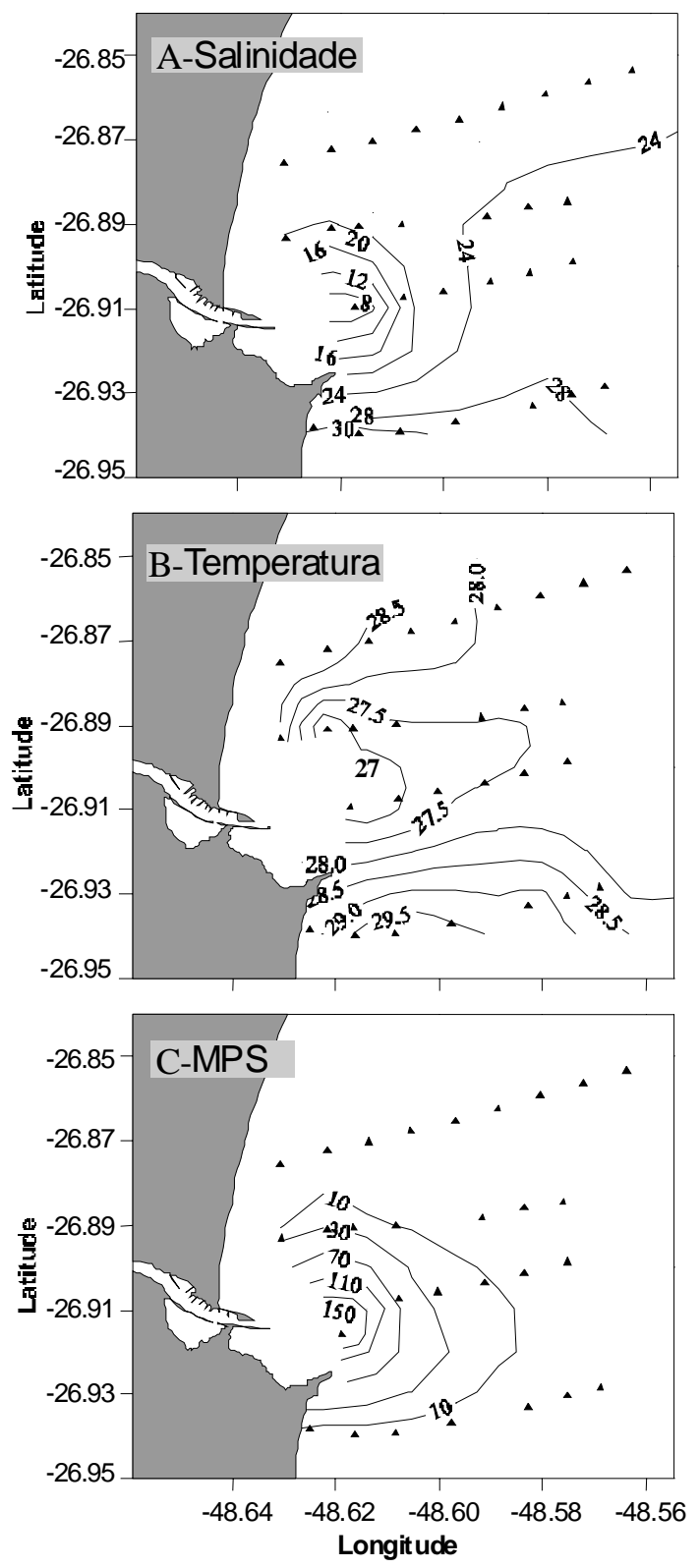

Figura 13 - Gráficos de distribuição espacial a $0.25 \mathrm{~m}$ na campanha do dia 17 de janeiro de 2000, sendo $A$, salinidade (psu), $B$, concentração de MPS (mg/l).
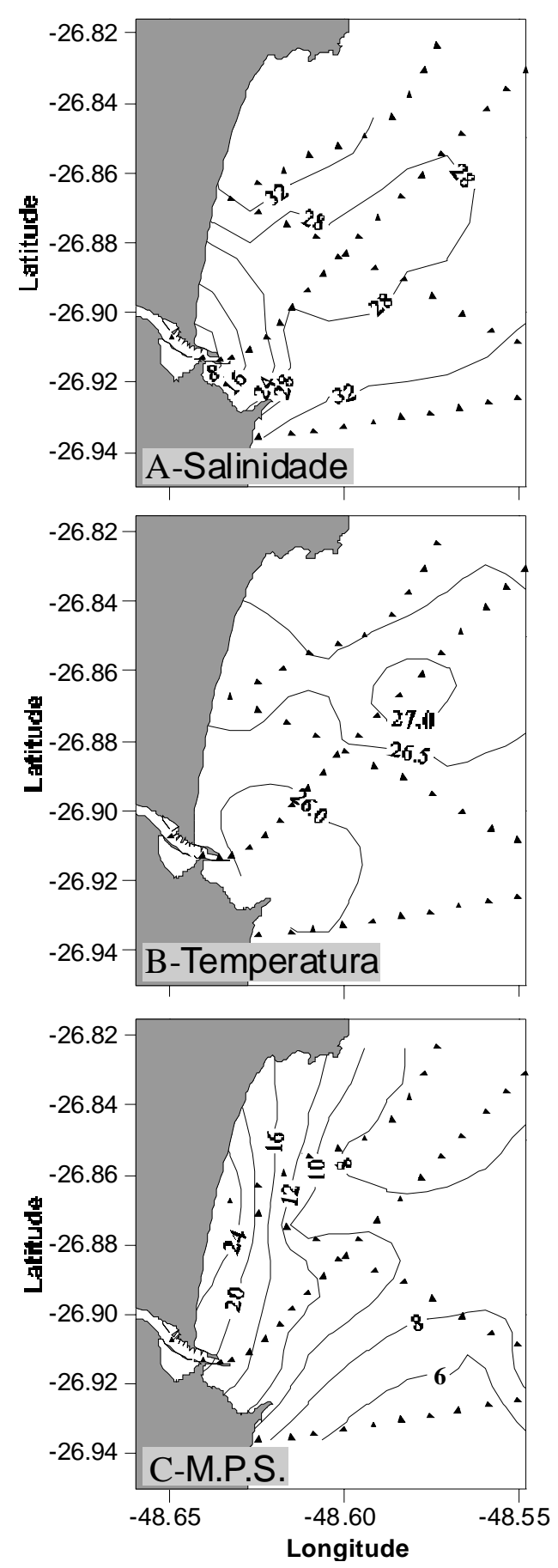

Figura 14 - Gráficos de distribuição espacial à $0.25 \mathrm{~m}$ na campanha do dia 25 de fevereiro, sendo $A$, salinidade (psu), $B$, temperatura $\left({ }^{\circ} \mathrm{C}\right)$ e, C, concentração de MPS. 
psu, observou-se um forte gradiente crescente de salinidade, o qual não se evidenciaram nas demais regiões (Figura 14a). O campo de temperatura na superfície apresentou temperaturas inferiores à $26^{\circ} \mathrm{C}$ logo após a desembocadura, aumentando a temperatura na região adjacente em sentido nordeste (Figura 14b).

\subsection{Campanha de março}

A Figura 15 apresenta a distribuição superficial de salinidade, temperatura e concentração de MPS.O campo de distribuição espacial de salinidade a -0.25 m apresentou nitidamente uma dispersão de baixa salinidade em direção nordeste, representada pela isohalina de 28 psu e uma retenção junto à costa principalmente a defronte a praia de Navegantes-SC. Um forte gradiente crescente de salinidade se desenvolveu após a desembocadura do estuário, entre salinidades de 8 psu e 24 psu (Figura 15a). O mesmo sentido de dispersão foi evidenciado no campo de temperatura através do gradativo aumento de temperatura entre as isotermas de 26 e 28 ○C (Figura 15b). O campo de distribuição espacial de MPS apresentou um gradiente aumentando no mesmo sentido dos demais parâmetros, sendo representado pela isolinha de 8 e $10 \mathrm{mg} / \mathrm{l}$. (Figura 15c).

\section{DISCUSSÃO}

\section{Caracterização geral das campanhas}

O rio Itajaí-açu possui a maior vertente atlântica do estado de Santa Catarina com uma descarga média de $228 \pm 282 \mathrm{~m}^{3} / \mathrm{s}$ (Schettini, 2002). Isto implica num contínuo transporte de materiais dissolvidos e particulados que irão ter seu destino influenciado pelas condições hidrodinâmicas do estuário e posteriormente pela pluma. A importância do estudo das plumas pode ser caracterizada através de diferentes aspectos, mas principalmente por ser um ambiente de exportação de matéria dissolvida e particulada do continente para o oceano, influenciando diretamente na qualidade ambiental do ecossistema costeiro adjacente a desembocadura. Até os dias atuais, poucos
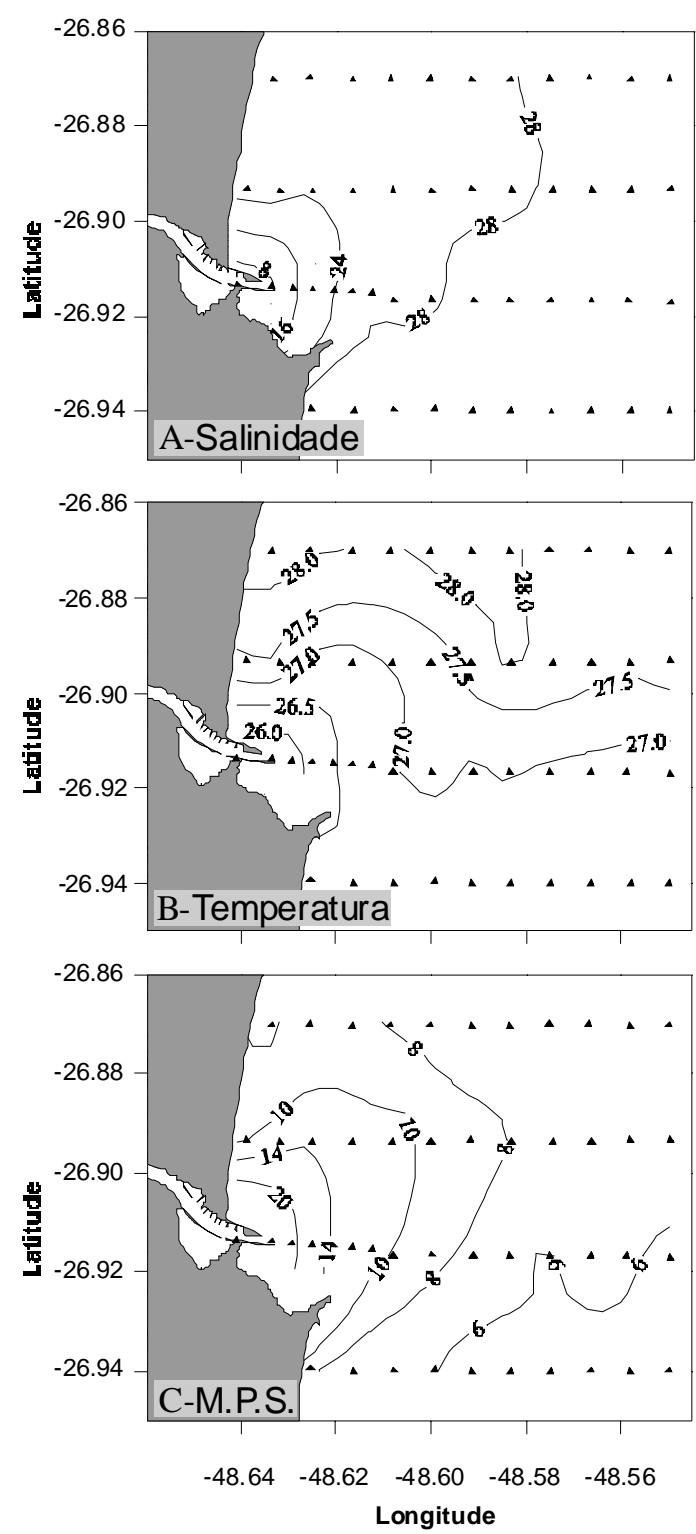

Figura 15 - Gráficos de distribuição espacial à $0.25 \mathrm{~m}$ na campanha de 14 de março, sendo $A$, salinidade (psu), $B$, temperatura $\left({ }^{\circ} \mathrm{C}\right)$ e, C, concentração de MPS. 
trabalhos têm sido realizados com plumas costeiras no Brasil, sendo os mesmos caracterizados principalmente como de caráter descritivo.

A pluma costeira reflete de forma direta os processos estuarinos, principalmente através da descarga fluvial. De acordo com os dados obtidos da estação limnimétrica de Indaial, a campanha de janeiro apresentou uma descarga fluvial entre moderada e alta com valor de $556 \mathrm{~m}^{3} / \mathrm{s}$, sendo que nas campanhas de fevereiro e março as descargas foram baixas, respectivamente apresentando valores de 227 e $214 \mathrm{~m}^{3} / \mathrm{s}$. A extensão da cunha salina dentro do estuário do rio Itajaí-açu é inversamente proporcional à descarga fluvial apresentando uma relação exponencial decrescente. Um modelo empírico proposto por Schettini \& Truccolo (1999) foi utilizado para se determinar a extensão da cunha salina dentro do estuário, o qual pode ser definido como: $E C=-1,72+$ $32,69 e^{(-0,00217 Q)}$, onde $Q$ é a descarga fluvial. Os valores corresponderam a 9,3, 18,9 e 19,4 $\mathrm{km}$, respectivamente para as campanhas de janeiro, fevereiro e março.

A extensão da cunha salina dentro do estuário está diretamente relacionada com a retenção de material proveniente da drenagem continental, logo os valores de concentração de MPS na pluma costeira deverão ser menores quanto maior for a extensão da cunha salina. Schettini (2001), relacionou empiricamente a taxa de retenção do estuário em função da descarga do rio, sendo $T R=0,84-7,6 e-4{ }^{*} Q$, onde TRé a taxa de retenção (\%), e $Q$ a vazão fluvial. A descarga sólida em suspensão (DSS) foi calculada pela fórmula $D S S=-5137+28,8$
$Q$ (Schettini, 2002). Através da DSS é possível estimar os valores de retenção e exportação de material (Tabela I). Os resultados mostraram que a quantidade de material retido e exportado no estuário é controlado principalmente pela vazão que influencia proporcionalmente a DSS, ou seja, quanto maior a energia cinética do sistema, maior a capacidade de transporte de material sólido em suspensão e maior a quantidade de material propício à precipitação. A influência da extensão da cunha salina na retenção de material é secundária, pois a baixa descarga que proporciona uma maior extensão da cunha também proporciona uma baixa DSS.

Caracteristicamente as plumas costeiras podem ser classificadas como plumas fluviais e estuarinas (Mann \& Lazier, 1991). Nas plumas fluviais a energia cinética adquirida pela descarga fluvial, caracterizada como advecção fluvial, prevalece sobre os processos oceanográficos promovendo uma alta estratificação dentro do estuário, com pouca mistura entre as massas de água e um lançamento de água doce diretamente sobre a água costeira. Nas plumas estuarinas as marés atuam dentro do estuário devido à baixa condição de descarga promovendo uma mistura representativa em toda a camada de água fluvial que escoa sobre a cunha salina, acarretando em um lançamento de água salobra sobre a água costeira. Na pluma da campanha de janeiro, como houve uma liberação direta de água doce, é considerável que os processos fluviais tenham predominado sobre os processos oceanográficos, sendo esta classificada como pluma fluvial (Figura 15a). Nas demais campanhas, a pluma é classificada

Tabela 1 - Vazão fluvial média de 5 dias $\left(\mathrm{m}^{3} / \mathrm{s}\right)$, sendo o último referente aos dias de campanhas, D.S.S. (ton/dia), extensão da cunha salina dentro do estuário $(\mathrm{km})$, retenção de sólidos em suspensão no estuário (ton/dia) e exportação para a plataforma interna adjacente a desembocadura do estuário (ton/dia).

\begin{tabular}{ccccccc}
\hline Campanha & Vazão & D.S.S & Ext. Cunha & Retenção & Exportação & TR \\
\hline Janeiro & 524 & 9942 & 8.8 & 4395 & 5547 & 0.44 \\
Fevereiro & 241 & 1801 & 17.7 & 1183 & 618 & 0.66 \\
Março & 231 & 1519 & 18.1 & 1009 & 510 & 0.66 \\
\hline
\end{tabular}


como estuarina devido aos processos oceanográficos proporcionarem uma mistura considerável da água fluvial acarretando na dispersão de água salobra (Figura 15bc).

Os frontes são caracterizados como sendo uma zona de convergência de água na interface da pluma com a água costeira onde ocorre a diluição da água entre as diferentes massas d'água principalmente pela difusão turbulenta. O principal fator responsável pela sua evolução é a relativa diferença entre as massas d'água que está diretamente relacionada com a quantidade de água de baixa salinidade lançada pela desembocadura do estuário (Bowden, 1983).

A presença de regiões de frontes foi mais representativa na campanha de janeiro devido ao aporte de água fluvial na região costeira apresentar-se superior que nas demais, também influenciado pelas descargas de dias anteriores. A proporção de água com baixa salinidade, quantitativamente superior na campanha de janeiro, promove um gradiente de densidade mais forte que nas campanhas de descarga inferior. Este gradiente após a desembocadura provoca a formação de regiões de convergência de água na interface entre a massa de água da pluma e a água costeira. Os diversos segmentos apresentados no diagrama T-S de janeiro indicam a presença de frontes que podem estar associados com zonas de convergência onde ocorrem a mistura das massas de água da pluma (Figura 15a). Esses segmentos tornam-se menos representativos nas campanhas de fevereiro e março devido ao baixo aporte fluvial na zona costeira com água salobra que conseqüentemente adquire uma densidade mais elevada, diminuindo o gradiente de densidade entre as massas d'água (Figura $15 \mathrm{bc}$ ).

\section{Distribuição superficial das variáveis}

A pluma fluvial de janeiro foi comparada com a pluma estuarina de março, porém devido à diferença de estratégia amostral na campanha de fevereiro não foi possível comparar, na totalidade, as campanhas de baixa descarga.

Os campos de distribuição de salinidade nas campanhas de baixa descarga apresentaram uma salinidade de 8 psu após a desembocadura, sendo que na campanha de janeiro, com descarga mais elevada, a isohalina de 8 psu encontra-se mais afastada da desembocadura. Este fato demonstra que nas campanhas de baixa descarga, o grau de mistura dentro do estuário é maior que na alta descarga (vide Figura 13a, 14a e 15a). A dispersão das plumas nas campanhas de janeiro e março apresentam-se em sentido
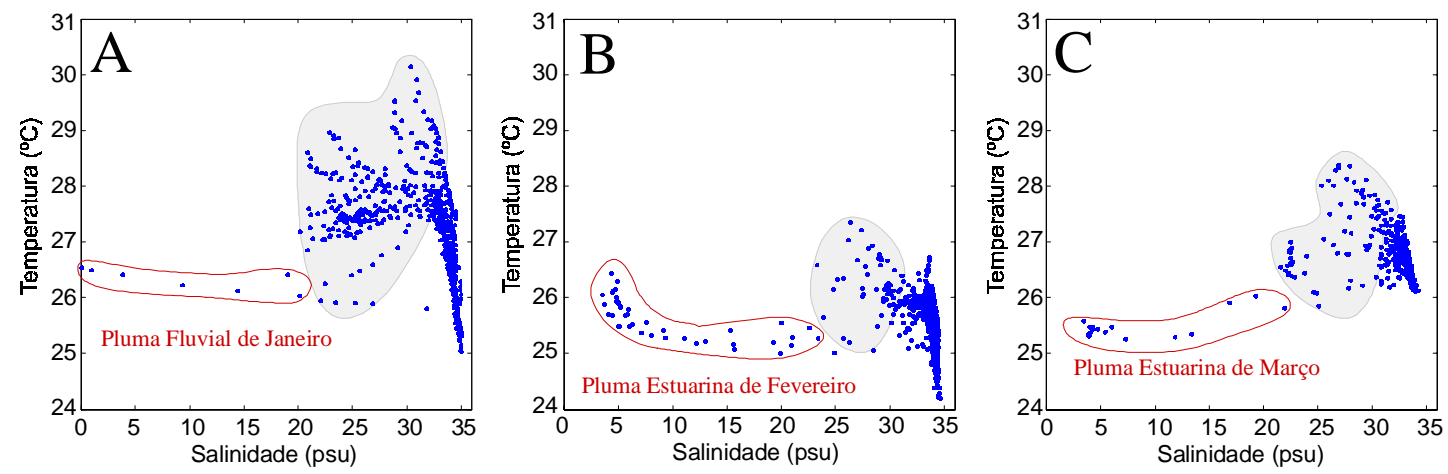

Figura 16 - Gráfico T-S com dados de salinidade e temperatura até 5 metros, sendo $A$, campanha de janeiro, $B$, campanha de fevereiro e, $C$, campanha de março. As regiões marcadas em conza indicam os locais de formação da água costeira e as regiões circundadas as plumas costeiras. 
nordeste, representado pela isolinha de $24 \mathrm{psu}$ na campanha de janeiro e pela isolinha de 28 psu na campanha de março, às quais também evidenciam uma maior distribuição de baixa salinidade em janeiro. Entre as campanhas de janeiro e fevereiro também observou-se que o forte gradiente de concentração após a desembocadura apresenta-se mais afastado da desembocadura na campanha de janeiro, fato este devido a advecção fluvial após a desembocadura apresentar-se superior que na campanha de fevereiro (vide Figura 13a e 15a).

Os campos de distribuição de temperatura apresentaram um gradiente crescente em direção norte nordeste na campanha de janeiro, enquanto que na campanha de março o gradiente apresenta um desvio à esquerda (vide figura 13b e 15b).

O campo de distribuição de concentração de MPS apresentou-se com concentrações mais elevadas na campanha de janeiro e uma dispersão mais representativa em direção ao mar aberto, enquanto que em março as concentrações apresentaram inferiores com uma retenção junto à costa. As elevadas concentrações após a desembocadura na campanha de janeiro são devido à maior descarga fluvial a qual promove uma maior ressuspensão de material particulado ao longo do curso do rio, o qual sofre pouca retenção no estuário devido à pequena na extensão da cunha salina (vide figura 13b e 15b).

\section{CONCLUSÃO}

Através da interpretação gráfica dos principais parâmetros que evidenciam a dispersão espacial da pluma do estuário do rio Itajaí-açu, podemos concluir que:

A influência da extensão da cunha salina na retenção de material é secundária, pois a baixa descarga que proporciona uma maior extensão da cunha também proporciona uma baixa descarga de sólidos em suspensão;
As variações de descarga fluvial do rio Itajaíaçu proporcionam a formação tanto de plumas fluviais como de estuarinas;

A concentração de MPS e a proporção de água doce na pluma costeira são proporcionais a descarga fluvial;

Independente da descarga fluvial das campanhas o desvio da água salobra da pluma do estuário do rio Itajaí-açu ocorre em direção norte-nordeste, assim como a sua retenção próximo a costa.

\section{REFERÊNCIAS BIBLIOGRÁFICAS}

Abreu, P. C., Granéli, H. W. \& C. Odebrecht. 1995. Produção fitoplanctônica e bacteriana na região da pluma estuarina da lagoa dos patos - RS, Brasil. Atlântica, Rio Grande, 17:35-52.

Bowden, K. F. 1983. Physical Oceanography of Coastal Waters. Ellis Horwood Series in Marine Science. Institute of Oceanographic Sciences, Wormley, Surrey,302 p.

Brandt, S. 2000. Salt wedge dynamics of Itajaíaçu estuary during a spring - Neap tidal cycle, SC, Brazil. Tese de Mestrado, Kiel, Alemanha, Institute of Geoscienses, Cristian Albrechts University, 98p.

Broche, P., Devenon, J., Forget, P., Maistre, J., Naudin, J. \& G. Cauwet. 1998. Experimental study of the Rhone plume. Part I: physics and dynamics. Oceanologica Acta. 21,6: 725-738.

Castro Fo, B. M. 1990. Estado atual do conhecimento dos processos físicos das águas da plataforma continental sudeste do Brasil. In: Simpósio de Ecossistemas Costeiros e Sudeste do Brasil, 2, Águas de Lindóia, Anais, ACIESP, p.1-11.

Froidefonde, J., Jegou, A., Hermida, J., Lazure, P. \& P. Casting. 1998. Variabilité du panade turbide de la Gironde par télédétection. Effets des facteurs climatiques. Oceanologica ACTA, 21(2):191-207. 
Garvine, R. W. 1987. Estuary plumes and fronts in shelf waters: A layer model. Journal of Physical Oceanography, 17:1877-1896.

Geyer, W. R., Beardsley, R. D., Candela, J., Castro Fo, B. M., Legeckis, R. V., Limeburner, R., Miranda, L. B. \& J. H. Trowbridge. 1991. The physical oceanography of the amazon outflow. Journal of Physical Oceanography, 19:1060-1072.

Geyer, W. R., Hill, P., Milligan, T. \& P. Traikvsky, 2000. The estructure of the eel river plume during floods. Jounal of Continental Coastal Research, 20: 2067-2093.

Hoekstra, P. 1989. Buoyant river plumes and mud deposition in a rapidly extending tropical delta. Netherlands Journal of Sea Research, 23 (49):517-527.

Hoyal, D. J. D., Bursik, M. I. \& J. F. Atkinson. 1999. The influence of diffusive convection on sedimentation from buoyant plumes. Marine Geology, 159: 205-220.

Mann, K. H. \& J. R. N. Lazier. 1991 Dynamics of marine ecosystems. Boston, Blackwell Scientific Publications, 466p.

Morehead, M. D. \& J. P. Syvitski. 1999. River plume sedimentation modeling for sequence stratigraphy: application to the Eel margin, northern California. Marine Geology, 154: 29-41.
Poulos, S. E. \& M. B. COLLINS. 1994. Effluent difusion and Sediment dispersion at microtidal river mouths, predicted using mathematical models. Estuarine, Coastal and Shelf Science, 38:189-206.

Schettini, C.A.F. 2001. Dinâmica de sedimentos finos no estuário do rio Itajaíaçu, SC. Tese de Doutorado, Porto Alegre, UFRGS/CECO, 85p.

Schettini, C.A.F 2002 Caracterização Física do Estuário do Rio Itajaí-açu. Revista Brasileira de Recursos Hídricos, Vol 7, p. 123-142.

Schettini, C.A.F., Kuroshima, K.N., Pereira Fo., J., Rörig, L.R. \& C. Resgalla Jr. 1998. Oceanographic and ecological aspects of Itajaí-açu river plume during a high discharge period. Anais da Academia Brasileira de Ciências, 70(2):335351.SCHETTINI, C.A.F 2002 Caracterização Física do Estuário do Rio Itajaí-açu. Revista Brasileira de Recursos Hídricos, Vol 7, p. 123-142.

Schettini, C. A. F. \& E. C. TRUCCOLO. 1999. Dinâmica da intrusão salina no estuário do rio Itajaí-açu. Congresso latino Americano de Ciências do mar, Vol 8, Trujilo, Peru, Resumes ampliados, Tomoll, UNT/ ALICMAR, p 639-640. 